\title{
Research on the Effects of AC Weak Interconnection of Power Grids on the Security, Stability and Emergency Control Under the Occurrence of Large-Capacity DC Blocking
}

\author{
Haijun Chang, Jie Dang, Xiancheng Ren, Youping Xu, Wei Li, Zhaojun Meng, and Jianghui Xi
}

\begin{abstract}
With the rapid development of the global economics, it is an inevitable trend for power grid development to adopt long-distance and large-capacity AC-DC parallel transmission. During the initial stage of power system interconnection, the security, stability and emergency control of AC weakly interconnected power transmission paths are affected by large-capacity DC blocking to a certain extent. Through constructing the typical operating modes of AC-DC hybrid grid, this paper analyzes the $\mathrm{AC}$-DC coupling effects and the characteristics of imbalance power allocation under the occurrence of large-capacity DC blocking, and further studies the impacts of interconnection of power grids on the security, stability and emergency control of $\mathrm{AC}$ interconnected power transmission paths under the occurrence of large-capacity DC blocking and elaborates the necessity of strengthening the coordinative development of AC-DC systems in the process of AC-DC interconnection of power grids, which provides the technical support for the planning, construction, and secure and stable operation of the interconnection of power grids.
\end{abstract}

Index Terms-AC-DC interaction, imbalance power, coupling, weak interconnection, security and stability.

\section{INTRODUCTION}

The interconnection of Power grids (IPG) is an inevitable trend for power system development all over the world, which realizes large-scale optimal allocation of energy and resources and provides significant economic benefits. Furthermore, ability of mutual support within a system has been enhanced when fault occurs , and then the power system operation reliability has also been enhanced [1]. Due to its distinct features such as long-distance and large-capacity power transmission, flexible adjustment, low power losses and so on, HVDC plays an important role in long-distance power transmission and large-scale IPG [2]-[5]. Consequently HVDC has been adopted in many power systems .However, the interaction between $\mathrm{AC}$ and $\mathrm{DC}$ system in an AC-DC hybrid power grid (ADHPG) is complicated [6]-[10]. Especially at the initial stage with

Manuscript received October 20, 2012; revised November 30, 2012

Haijun Chang, Xiancheng Ren, Wei Li, and Zhaojun Meng are with China Electric Power Research Institute, Nanjing, 210003 China (e-mail: changhaijun@epri.sgcc.com.cn, renxiancheng@epri.sgcc.com.cn, liwei@epri.sgcc.com.cn, mengzhaojun@epri.sgcc.com.cn).

Jie Dang, Youping $\mathrm{Xu}$, and Jianghui Xi are with Central China Power System Dispatching \& Control Branch Center, Wuhan, 430077 China(e-mail: dangj@cc.sgcc.com.cn, xuyp@cc.sgcc.com.cn, xijh@cc.sgcc.com.cn). weak AC interconnection of power grids, when high DC power is transferred to AC power transmission paths (PTPs) due to the occurrence of large-capacity DC blocking (LDCB), voltages and power angles of associated key AC PTPs may face great challenge, and relatively weak AC PTPs may lose stability. With the IPG, power transferring under the occurrence of LDCB may present new characteristics, which causes certain impacts on the security, stability and emergency control (SSEC) of AC PTPs. Researches on the characteristics of imbalance power allocation (IPA) for the IPG under the occurrence of LDCB and associated impacts on the SSEC of AC PTPs will make a great guidance for IPG.

Through constructing the typical operating modes (OMs) of AC-DC hybrid grid, this paper analyzes the AC-DC coupling effects and the characteristics of IPA under the occurrence of LDCB, further studies the impacts of IPG on the SSC of AC PTPs, and elaborates the necessity of strengthening the coordinative development of AC-DC systems during the construction process of the ADHPG.

\section{THE EFFECTS OF IPG ON IPA UNDER THE OCCURRENCE} OF LDCB

Fig.1 shows the canonical schema of a constructing planning IPG, in which the $\mathrm{DC} 2$ in power grid $\mathrm{B}$ is a multi-HVDC, transfers power to power grid $\mathrm{C}$, and the typical OMs are constructed as follows:

With the typical OM-1, power grid A transfers 5,000MW to power grid $\mathrm{B}$, and power grid A transfers $5,000 \mathrm{MW}$ to power grid $\mathrm{C}$. The DC1, which is a bipolar HVDC in power grid $\mathrm{D}$ transfers $8,000 \mathrm{MW}$ to power grid $\mathrm{B}$, the $\mathrm{DC} 3$, which is also a bipolar HVDC in power grid $\mathrm{B}$, transfers $3,000 \mathrm{MW}$ to power grid E, and the multi-HVDC of DC2 transfers $6,300 \mathrm{MW}$ to power grid C.

With the typical OM-2, power grid B transfers 5,500MW to power grid A, and power grid A transfers $4,000 \mathrm{MW}$ to power grid C. The multi-HVDC of DC2 transfers 13,200MW to power grid $\mathrm{C}$, and the power of other DCs transmission is as the typical OM-1.

With the typical OM-3, power grid B transfers 5,000MW to power grid A, and the power of other AC PTPs and DCs transmission is as the typical OM-2.

Combining aforementioned the planning IPG, this paper focuses on the study that the effects after the interconnection of power grids $\mathrm{A}, \mathrm{B}$ and power grid $\mathrm{C}$ through PTP-AC, which is referred to as inter-ABC, on the security and 
stability of PTP-AB under the occurrence of LDCB in power grid B.

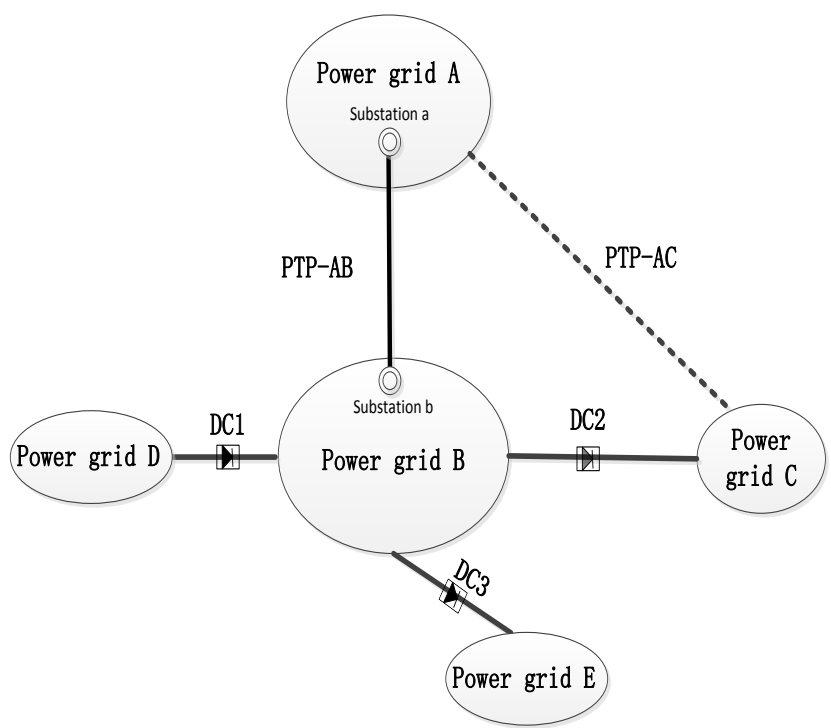

Fig. 1. The canonical schema of a constructing planning IPG

When imbalance power is induced under the occurrence of LDCB in power grid $\mathrm{B}$, compared to those before the inter-ABC, the characteristics of IPA change as follows:

1) After the inter-ABC, significantly more $\mathrm{DC}$ power has been transferred to the PTP between power grids A and $\mathrm{B}$ (PTP-AB), under the occurrence of LDCB for DC2, during the transient and steady states, compared to that before the inter-ABC.

2) After the inter-ABC, under the occurrence of LDCB for $\mathrm{DC} 1$ or $\mathrm{DC} 3$, power grids $\mathrm{A}, \mathrm{B}$ and $\mathrm{C}$ share the induced imbalance power. Compared to that before the inter-ABC, more imbalance power will be shared by the power grid A side, which causes more power to be transferred through PTP-AB, during the transient and steady states.

With the typical OMs, Table I compares the power responses of $\mathrm{PTP}-\mathrm{AB}$ before the inter-ABC with those after the inter-ABC, under the occurrence of LDCB.

TABLE I: POWER RESPONSE OF PTP-AB BEFORE AND AFTER THE INTER-ABC, UNDER THE OCCURRENCE OF LDCB

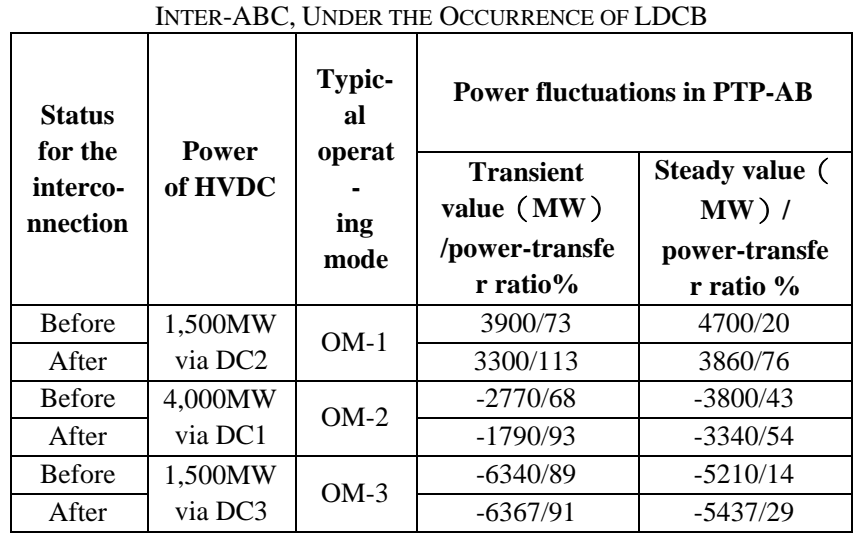

\section{IMPACTS ON POWER SYSTEM SECURITY AND STABILITY}

The impacts of aforementioned characteristics of IPA on power system security and stability are summarized as follows:
1) Compared to that before the inter- $A B C$, after the inter-ABC, under the occurrence of $\mathrm{LDCB}$ for $\mathrm{DC} 2$, which transfers power from grid $\mathrm{B}$ to $\mathrm{C}$, under the $\mathrm{OM}-1$, due to the aggravation of power transferring to $\mathrm{PTP}-\mathrm{AB}$, voltage drops at PTP-AB become more serious, and under severe circumstances the generating units in power grid B may lose angle stability; and on the other hand, under the OM-2, voltage magnitudes increase more at $\mathrm{PTP}-\mathrm{AB}$.

2) Compared to that before the inter- $A B C$, after the inter-ABC, under the occurrence of LDCB for DC1, which transfers power into grid $\mathrm{B}$, more power will be transferred via $\mathrm{PTP}-\mathrm{AB}$ due to that power grids $\mathrm{A}, \mathrm{B}$ and $\mathrm{C}$ shares the power shortage. Under the OM-1, voltage drops at PTP-AB become more serious, and under severe circumstances the generating units in power grids $\mathrm{A}$ and $\mathrm{C}$ may lose angle stability; and on the other hand, under the OM-2, voltage magnitudes increase more at PTP-AB.

3) Compared to that before the inter- $A B C$, after the inter-ABC, under the occurrence of $\mathrm{LDCB}$ for $\mathrm{DC} 3$, which transfers power out of grid $\mathrm{B}$, more power will be transferred via PTP-AB due to that power grids $\mathrm{A}, \mathrm{B}$ and $\mathrm{C}$ shares the power surplus. Under the OM-2 or OM-3, voltage drops at PTP-AB become more serious, and under severe circumstances the generating units in power grid B may lose angle stability; and on the other hand, under the OM-1, voltage magnitudes increase more at PTP-AB.

Fig. 2 compares steady-state voltage responses of substation $\mathrm{a}$ and $\mathrm{b}$ before and after the inter-ABC under the occurrence of LDCB (under the typical OMs).

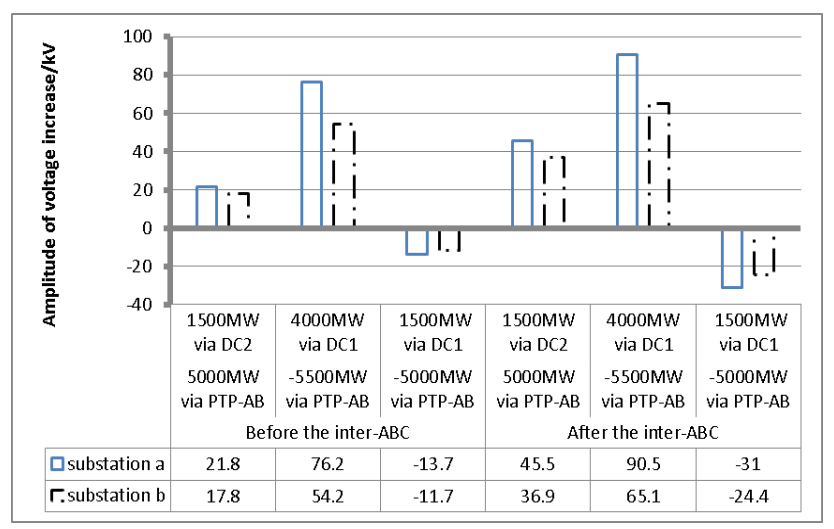

Fig. 2. Steady-state voltage responses of substation a and $b$ under the occurrence of LDCB before and after power grids interconnection(Power grid A transmitting to power grid B is positive)

\section{IMPACTS ON THE DEGREEE OF AC-DC COUPLING}

The transient angle stability limit is one of key constraints of transmission capacity of AC-DC hybrid system, in which the instability mode is a very important concept to characterize the constraining factors. An instability system always separates into a cluster of critical machines (cluster-S) and of non-critical machines (cluster-A) [11]. And the cluster-S usually stands for the instability mode. Affected by the characteristics of IPA under the occurrence of LDCB and angle stability limit constraints for key PTPs, certain coupling effects exist between DC power transfer and power transferred via correlated key PTPs. After the inter-ABC, due to the change of IPA under the occurrence of LDCB, these effects vary accordingly and furthermore the correlated 
key PTPs may also vary, as show in Table II.

1) Under the OM-1, affected by the angle stability limit constraints of generating units of grid $\mathrm{A}$ and $\mathrm{C}$ relative to grid $\mathrm{B}$ under the occurrence of DC1 blocking and the aggravation of power transferred to PTP-AB, the coupling effects between DC1 and PTP-AB become stronger.

2) Affects by the angle stability limit constraints of units of power grid $\mathrm{B}$ relative to power grid $\mathrm{A}$ and $\mathrm{C}$ under the occurrence of LDCB and the aggravation of power transferred to PTP-AB, the coupling effects between DC2 and PTP-AB become stronger. Furthermore, under the OM of grid $\mathrm{B}$ transferring less power to grid $\mathrm{A}$ or power grid $\mathrm{A}$ transferring power to grid $\mathrm{B}$, if grid $\mathrm{A}$ transfers more power to power grid $\mathrm{C}$, there exists certain coupling effects between DC2 and PTP-AC.

3) Affected by the angle stability limit constraints of units of power grid $\mathrm{B}$ relative to power grid $\mathrm{A}$ and $\mathrm{C}$ under the occurrence of LDCB and the aggravation of power transferred to PTP-AB, the coupling effects between DC3 and PTP-AB become stronger.

TABLE II. THE COUPLing EFFeCts BETwEen DC AND Key PTPs Before

\begin{tabular}{|c|c|c|c|}
\hline \multicolumn{4}{|c|}{$\frac{\text { AND AFTER THE INTER-ABC }}{\text { DC1 (before/after inter-ABC) }}$} \\
\hline $\begin{array}{l}\text { Power of } \\
\text { PTP-AB }\end{array}$ & $\begin{array}{c}1300 / 600(\mathrm{~A} \\
\text { to } \mathrm{B})\end{array}$ & \multicolumn{2}{|c|}{$5000(\mathrm{~A}$ to $\mathrm{B})$} \\
\hline $\begin{array}{l}\text { Power of } \\
\text { LDCB }\end{array}$ & 8000 & \multicolumn{2}{|c|}{$2900 / 2500$} \\
\hline $\begin{array}{c}\text { Instability } \\
\text { Mode(cluster-S) }\end{array}$ & \multicolumn{3}{|c|}{ power grid $\mathrm{A}(\mathrm{A}, \mathrm{C})$} \\
\hline \multicolumn{4}{|c|}{ DC2 (before/after inter-ABC) } \\
\hline $\begin{array}{l}\text { Power of } \\
\text { PTP-AB }\end{array}$ & $\begin{array}{l}4900 / 2800(\mathrm{~B} \\
\text { to } \mathrm{A})\end{array}$ & $\begin{array}{l}\text { 5500(B to } \\
\text { A) }\end{array}$ & $15000(\mathrm{~A}$ to $\mathrm{B})$ \\
\hline $\begin{array}{l}\text { Power of } \\
\text { PTP-AC }\end{array}$ & $\begin{array}{l}-/ 4000(\text { A to } \\
\text { C) }\end{array}$ & $\begin{array}{l}-/ 4000(\mathrm{~A} \\
\text { to } \mathrm{C})\end{array}$ & $14100(\mathrm{~A}$ to $\mathrm{C})$ \\
\hline $\begin{array}{l}\text { Power of } \\
\text { LDCB }\end{array}$ & 3000 & $2000 / 600$ & 3000 \\
\hline $\begin{array}{c}\text { Instability } \\
\text { Mode(cluster-S) }\end{array}$ & \multicolumn{2}{|c|}{ power grid B } & power grid A,B \\
\hline \multicolumn{4}{|c|}{ DC3 (before/after inter-ABC) } \\
\hline $\begin{array}{l}\text { Power of } \\
\text { PTP-AB }\end{array}$ & \multicolumn{2}{|c|}{$3900 / 3600(\mathrm{~B}$ to $\mathrm{A})$} & $5500(\mathrm{~B}$ to $\mathrm{A})$ \\
\hline $\begin{array}{l}\text { Power of } \\
\text { LDCB }\end{array}$ & \multicolumn{2}{|c|}{3000} & $1600 / 1000$ \\
\hline $\begin{array}{c}\text { Instability } \\
\text { Mode(cluster-S) }\end{array}$ & \multicolumn{3}{|c|}{ power grid B } \\
\hline
\end{tabular}

\section{IMPACTS ON EMERGENCY CONTROL OF POWER SySTEM}

After the inter-ABC, the characteristics of IPA and their impacts on the security and stability of power system vary, and their impacts on the transient stability emergency control of power system vary accordingly, which is shown as follows:

1) After the inter-ABC, when power transferred via PTP-AB varies, under the occurrence of LDCB for DC2 more power will be transferred to AC PTPs. If DC power modulation (PM) is adopted as a SSC measure for accidents occurring on PTP-AB, the control measure will be simultaneously applied to both sending-end and receiving-end power grids. The control effect is significantly better than that before the inter- $\mathrm{ABC}$, and the required amount of DC PM can be reduced correspondingly.

2) One phenomenon should be noted. After the inter-ABC, under the $\mathrm{OM}-1$, if an accident resulting in large power shortage of power grid B occurs and power modulation for DC2 is adopted as the control measure, the stability of PPTs between grid A and grid C (PPT-AC) must be observed. A large amount of PM for DC2 could result in the loss of stability for PPT-AC.

For example, under the OM-1, after the inter-ABC, PTP-AC loses stability to adopt the measure of decreasing $5,000 \mathrm{MW}$ of DC2 transmission power under the occurrence of LDCB for DC1 as show in Fig.3.

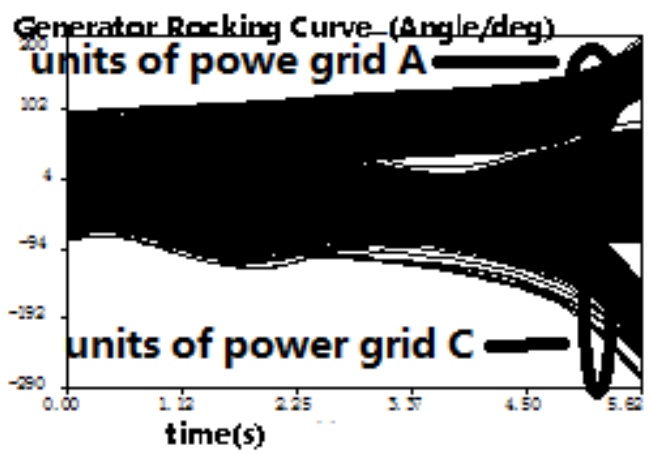

Fig. 3. The response curve of angle after decreasing 5,000MW of DC2 transmission power under the occurrence of DC1 bipolar blocking

3) After inter-ABC, affected by the aggravation of power transferred to PTP-AB under the occurrence of LDCB in power grid $\mathrm{B}$, the required amount of security and stability control measure (except for the PM for DC2) need to be increased correspondingly.

For example, under the OM-1 and the occurrence of DC1 monopole blocking, Table III compares the required amount of emergency control after the inter- $\mathrm{ABC}$ with that before the inter-ABC.

For example, under the OM-1 and the occurrence of DC1 monopole blocking, Table III compares the required amount of emergency control after the inter- $\mathrm{ABC}$ with that before the inter-ABC.

TABLE III: THE EXTENT OF ANGLE INSTABILITY AND THE REQUIRED

AMOUNT OF EMERGENCY CONTROL (UNDER THE OM-1 AND THE OCCURRENCE OF DC1 MONOPOLE BLOCKING)

\begin{tabular}{|c|c|c|c|c|c|}
\hline \multicolumn{2}{|c|}{ Faul } \\
$-\begin{array}{c}\text {-t } \\
\text { ftatus } \\
\text { interco- } \\
\text { nnection }\end{array}$ & $\begin{array}{c}\text { Instability } \\
\text { Mode(clus } \\
\text { ter-S) }\end{array}$ & $\begin{array}{c}\text { Angle } \\
\text { stabi- } \\
\text { lity } \\
\text { margi } \\
\text { n /(\%) }\end{array}$ & $\begin{array}{c}\text { Load } \\
\text { shed- } \\
\text { ing } \\
\text { in power } \\
\text { grid B }\end{array}$ & $\begin{array}{c}\text { Decre- } \\
\text { ment } \\
\text { of PM } \\
\text { for } \\
\text { DC2 }\end{array}$ \\
\hline $\begin{array}{c}\text { DC1 } \\
\text { mono } \\
- \\
\text { pole } \\
\text { block } \\
\text {-ing }\end{array}$ & Before & $\begin{array}{c}\text { power grid } \\
\text { A }\end{array}$ & -80.79 & $1,200 \mathrm{MW}$ & $\begin{array}{c}1,200 \mathrm{M} \\
\mathrm{W}\end{array}$ \\
\cline { 2 - 6 } & After & $\begin{array}{c}\text { power grid } \\
\text { A,C }\end{array}$ & -99.55 & $1670 \mathrm{MW}$ & $\begin{array}{c}1,000 \mathrm{M} \\
\mathrm{W}\end{array}$ \\
\hline
\end{tabular}

As show in Table III, compared to that before the inter- $\mathrm{ABC}$, under the occurrence of $\mathrm{DC} 1$ monopole blocking, after the inter-ABC, the extent of angle instability becomes more severe with $-99.55 \%$ of the angle stability margin based the extended equal area criterion (EEAC), which is a rigorous quantitative method, which can quickly assess stability limits with sensitivity analysis [12], and the required amount of 
load shedding increases correspondingly. On the other hand, if DC PM is adopted for emergency control, after the inter- $\mathrm{ABC}$, the required decrement of $\mathrm{PM}$ for $\mathrm{DC} 2$ is less than that before the inter-ABC.

\section{SUMMARIES}

To realize coordination and efficient utilization of energy and resources in wide areas, long-distance, large-capacity and cross-regional AC-DC interconnection is an inevitable trend for large power grid development. During the initial period of AC-DC interconnection, large capacity and cross-regional DC power transmission could be interconnected with weak AC PTPs. Under such a situation, affected by the characteristics of IPA under the occurrence of LDCB, there exists strong coupling effects between AC PTPs and DC system, and the occurrence of LDCB could have major effects on power system security and stability.

Through the analysis of the typical operating modes of AC-DC hybrid grid, this paper analyzes the characteristics of IPA and the coupling effects between $\mathrm{AD}$ and $\mathrm{DC}$ transmission systems under the occurrence of LDCB, and this paper also studies the impacts of IPG on the SSEC of AC PTPs under the occurrence of LDCB. These studies point out the necessity of strengthening the intensity of interconnection among power grids $\mathrm{A}, \mathrm{B}$ and $\mathrm{C}$ during the construction process of IPG, and the necessity of coordinated development of AC and DC transmission systems. These studies provide valuable technical support for the planning and construction of IPG.

\section{REFERENCES}

[1] Z. X. Han, Y. S. Xue, and J. J. Qiu, "Transient Stability Analysis of Parallel AC/DC System," Automation of Electric Power Systems, China, vol. 24, no. 24, pp.1-4, 2000.

[2] H. Tian, "The Feature Development and Application of Direct Current Transmission Techniques," Shandong Electric Technology, China, vol. 1, pp. 29-32, 2003.

[3] Y. H. Peng, "Development and prospect of HVDC Transmission," Hunan Electric, China, vol. 27, no. 1, pp. 52-57.

[4] S. J. Chen, "Advantage and Prospect of DC transmission," Hydropower Plant Design, China, vol. 27, no. 1, pp. 52-57.

[5] Z. Y. Liu, UHVDC Power Transmission Theory, Beijing, China Electric Power Press, 2009.

[6] B. R. Zhou, X. M. Jin, X. C. Wu et al, "Influence of UHVDC System on the Security and Stability of AC/DC Interconnected Power Grid," Southern Power System Technology, China, vol. 4, no. 2, pp. 31-34, 2010.

[7] Z. Xu, Dynamic Behaviors Analyzing of AC/DC Power Systems, Beijing, Beijing, China Machine Press, 2004.

[8] S. Lefebver, A. M. Gole, J. Reeve et al, "Working Group on Dynamic Performance and Modeling of DC Systems and Power Electronics for Transmission Systems-Report on Test Systems for AC/DC Interaction Studies," IEEE Transactions on Power Delivery, vol. 10, no. 2, pp. 2027-2034, 1995.

[9] J. S. Zhang, Y. Zhang, Z. C. Zhang et al, "Voltage Stability Study of Parallel AC/DC Power Systems," Relay, China, vol. 33, no. 2, pp.79-84, 2005.

[10] P. Kunder, Power System Stability and Control New York McGraw-Hill, 1994.

[11] W. Li, Y. Xue, and D. J. Hill, "Optimization of Transient Stability Control Part-II: For Cases with Different Unstable Modes," in Proc. the $6^{\text {th }}$ International Conf. APSCOM 2003, Hong Kong, pp. 782-786.

[12] Y. S. Xue, Quantitative Study of General Motion Stability and an Example on Power System Stability (in Chinese), Jiangsu Science and Technology Press, Nanjing, China, 1999.

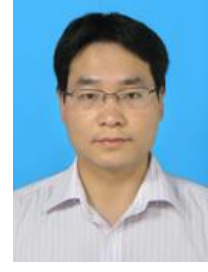

Haijun Chang became a Member of IEEE in 2012. He was born in Anyang, China on August 29, 1981. He received the MS degree in Electrical Engineering from Hohai university, China, in 2010. From June, 2010 to February, 2012, he was a Research Assistant at State Grid Electric Power Research Institute, China, and then became Assistant Engineer at China Electric Power Research Institute (CEPRI)till now. His current research control. interest is power system security and stability analysis and

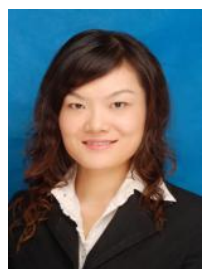

Jie Dang was born in Nanyang, China in 1981. She received the MS and Ph.D. degrees in Electrical Engineering from Wuhan University, China. She is now the power stability specific duty in the System Operation department of Central China Power System Dispatching \& Control Branch Center. Her current research interest is power grid operation analysis and calculation.

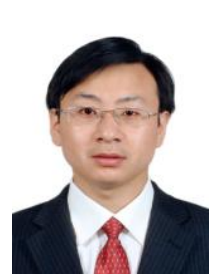

Xiancheng Ren was born in Xinzhou, Shanxi, China, in 1980. He received the BS and MS degrees in Electrical Engineering from Taiyuan University of Technology, China, in 2001 and2004 respectively, and the $\mathrm{Ph} . \mathrm{D}$. degree from Southeast University, China, in 2009. He has published more than 10 technical papers in the international or national journals. His current research interest is large power system stability analysis and control.

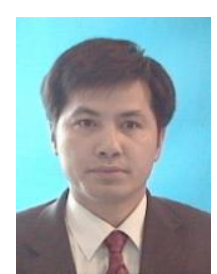

Youping Xu was born in Huanggang, China, in 1970. $\mathrm{He}$ received the BS and MS degrees in Huazhong University of Science and Technology. He is now the section chief of the System Operation department of Central China Power System Dispatching \& Control Branch Center. His current research interest is power grid operation analysis and management.

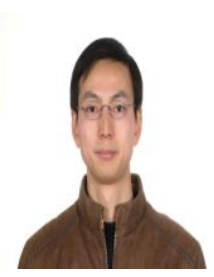

Wei Li became a Member of IEEE in 2008. He was born in Xuzhou, China. He received the BS and MS degrees inElectrical Engineering from Harbin Institute of Technology, China, in 1998 and2000 respectively,and the $\mathrm{Ph} . \mathrm{D}$. degree from Zhejiang University, China, in 2004. He is currently the director of the Research institute of China Electrical Power Research Institute (CEPRI). He has published more than 30 technical papers in the international and national, conferences and journals. His current research interest is large power system stability analysis and control.

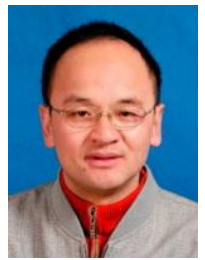

Zhaojun Meng was born in Xining, China on May 1, 1973. He obtained B.Eng. from North China Institute of Electric Power, M.Eng. from Wuhan University of Hydraulic and Electric Engineering and Nanyang Technological University, and Ph.D. from the University of Strathclyde. He is now with China Electric Power Research Institute, and his major research field is focused on the analysis and control of power system stability.

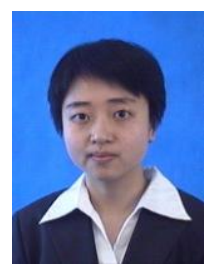

Jianghui Xi was born in china, in 1975. She received the BS and MS degrees in Huazhong University of Science and Technology. She is now the deputy chief of the System Operation department of Central China Power System Dispatching \& Control Branch Center. Her current research interest is power grid operation analysis and management. 